and gastrojejunostomy makes it difficult for us to suggest a policy of follow up for these patients in general. We intend to perform endoscopy about every six months in patients with severe dysplasia and every year in those with moderate dysplasia. We are not convinced of the value of frequent endoscopic follow up in those of our patients in whom we found other histological abnormalities. Even though we found no case of infiltrating carcinoma, the high incidence of dysplasia in our patients is disturbing, especially in view of the fact that the average time of our follow up was only 21 years. We fear that a high incidence of gastric carcinoma may emerge 25 years after patients have undergone vagotomy and gastroenterostomy.

PCHW was in receipt of a Royal Victoria Hospital fellowship throughout the study. Mr C C Patterson, department of medical statistics, Queen's University, Belfast, advised on statistical analysis. Mr J Reid and staff of the histopathology laboratory, department of pathology, Royal Victoria Hospital, made all the microscopic slides. We thank Smith, Kline and French Research Ltd and the Mater Infirmorum Hospital gifts and endowment fund for financial support.

\section{References}

${ }^{1}$ Schrumpf E, Serck-Hanssen A, Stadaas J, Aune S, Myren O, Osnes M. Changes in the gastric stump, 20-25 years after partial gastrectomy. Lancet 1977 ;ii:467-9.

${ }^{2}$ Domellof L, Eriksson S, Janunger K-G. Late precancerous changes and carcinoma of the gastric stump after Billroth I resection. Am $\mathcal{F}$ Surg 1976;132:26-31.

${ }^{3}$ Domellof L, Eriksson S, Janunger K-G. Carcinoma and possible precancerous changes of the gastric stump after Billroth II resection. Gastroenterology $1977 ; 73: 462-8$.

4 Peitsch W, Becker HD. Was ist gesichert in der Pathogenese und Häufigkeit des primären Carcinoms im operierten Magen? Chirurg $1979 ; 50: 33-8$.
${ }^{5}$ Welvaart $\mathrm{K}$, Warnsinck HM. The incidence of carcinoma of the gastric remnant. F Surg Oncol 1982;21:104-6.

${ }^{6}$ Morson BC, Soben CH, Grundmann E, Johanson A, Nagayo T, SerckHanssen A. Precancerous conditions and epithelial dysplasia in the stomach. F Clin Pathol 1980;33:711-21.

' Peitsch W, Becker HD. Frequency and prognosis of gastric stump cancer. Front Gastrointest Res 1979;5:170-7.

${ }^{*}$ Stalsberg H, Taksdal S. Stomach cancer following gastric surgery for $\mathbb{D}$

benign conditions. Lancet $1971 ;$ ii $: 1175-9$.
${ }^{y}$ Ross HAM, Smith MA, Anderson JR, Small WP. Late mortality after $气$ surgery for peptic ulcer. $N$ Engl $\mathcal{F}$ Med $1982 ; 307: 519-22$.

${ }^{10}$ Morgenstern L, Yamakawa T, Seltzer D. Carcinoma of the gastric stump. Am f Surg 1973;125:29-38.

11 Morson BC, Dawson IMP. Gastrointestinal pathology. 2nd ed. London: Blackwell Scientific, 1979:152.

12 Farrands PA, Blake JRS, Ansell ID, Cotton RE, Hardcastle JD. Endoscopic $\overline{\bar{\omega}}$ review of patients who have had gastric surgery. Br Med $\mathcal{f} 1983 ; 286:$ :
$755-8$.

13 Serck-Hanssen A. Precancerous lesions of the stomach. Scand F Gastro- @ֶ) enterol [Suppl] 1979;14:104-5.

${ }^{14}$ Morson BC. Carcinoma rising from areas of intestinal metaplasia in the $\overrightarrow{0}$ gastric mucosa. Br f Cancer 1955;9:377-85.

${ }^{15}$ Cheli $\mathrm{R}$, Simon L, Asth $\mathrm{H}$, et al. Atrophic gastritis and intestinal metaplasia $\vec{\omega}$ in asymptomatic Hungarian and Italian populations. Endoscopy 1980; O 12:105-8.

${ }^{16}$ Correa P, Cuello C, Duque E. Carcinoma and intestinal metaplasia of the stomach in Columbian migrants. FNCI 1970;44:297-306.

17 Siurala M, Varis K, Wiliasalo M. Studies of patients with atrophic $\underset{\mathcal{N}}{\mathcal{N}}$ gastritis: a 10-15 year follow-up. Scand 7 Gastroenterol 1966;1:40-8.

18 Johnston DH. Blind gastric and duodenal mucosal biopsies on patients with duodenal ulcer and those with an ulcer-like syndrome. Southern Medical fournal 1964;57:79-84.

19 Domellof L, Reddy BS, Weisburger JH. Microflora and deconjugation $\vec{A}$ of bile acids in alkaline reflux after partial gastrectomy. Am $\mathcal{f}$ Surg $\bigcirc$ 1980;140:291-5.

${ }^{20}$ Reed PI, Smith PLR, Haines K, House FR, Walters CL. Gastric juice $\mathrm{N}$-nitrosoamines in health and gastroduodenal disease. Lancet 1981;i: $\vec{N}$ 550-2.

${ }^{21}$ Milton-Thompson GJ, Lightfoot NF, Ahmet L, et al. Intragastric $O$ acidity, bacteria, nitrite and $\mathrm{N}$-nitroso compounds before during and $\Phi$ after cimetidine treatment. Lancet 1982 ; : 1091-5.

(Accepted 2 August 1983)

\title{
Histology of the postoperative stomach before and after diversion of bile
}

\author{
P C H WATT, J M SLOAN, ANNE SPENCER, T L KENNEDY
}

\begin{abstract}
Gastric biopsy specimens were taken in 33 patients before and after procedures to divert bile (construction of Roux loop in 19, closure of gastrojejunostomy in 14). Each biopsy specimen was assessed for dysplasia, intestinal metaplasia, atrophy, and gastritis, each variable being given a score ranging from 0 to 6 . Patients were given
\end{abstract}

Departments of Surgery and Pathology, Queen's University, Belfast P C H WATT, MB, FRCS, research fellow

J M SLOAN, MD, MRCPATH, consultant pathologist

Royal Victoria Hospital, Belfast

ANNE SPENCER, $\mathrm{MB}, \mathrm{BCH}$, research assistant

T L KENNEDY, $M C H$, FRCS, consultant surgeon

Correspondence to: Mr P C H Watt, Department of Surgery, Queen's University of Belfast, Institute of Clinical Science, Grosvenor Road, Belfast BT 12 6BJ. preoperative and postoperative scores for each of these variables based on the average score of all preoperative or postoperative specimens. Comparison between pre- 0 operative and postoperative histology showed that there $\stackrel{3}{J}$ was no difference for gastritis, atrophy, or intestinal $N$ metaplasia. Patients who underwent closure of a gastro- $\rightarrow$ jejunostomy showed improvement in dysplasia that was not statistically significant. There was, however, a $N$ significant improvement in dysplasia in patients in whom N a Roux loop was fashioned $(p=0.006)$ and in all patients $O$ taken together $(p=0.002)$.

It was concluded that procedures that divert bile $\stackrel{?}{=}$

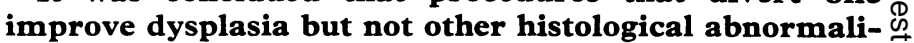
ties in the stomach postoperatively.

\section{Introduction}

Gastric mucosal dysplasia has recently given cause for concern because of its possible premalignant potential. ${ }^{12}$ After operation $\delta$ the stomach appears to be especially prone to this abnormality. ${ }^{3}$ Domellof suggested that reflux of bile into the stomach after $\frac{0}{\partial}$ 
operation may lead to premalignant and even malignant change after many years. ${ }^{4}$ His centre showed the presence of unconjugated and secondary bile acids in patients after gastrectomy, ${ }^{5}$ some of which promote colonic adenocarcinoma in experimental animals. ${ }^{6}$ Enterogastric reflux of bile has also been suggested as a cause of gastritis in the stomach after operation.? One study showed a correlation between the quantity of bile reflux and the degree of gastritis, ${ }^{8}$ thus giving justification to the term "malevolent gall" coined by Silen. "It is not known whether the histological changes in the stomach after operation are reversible. The aim of this study was to investigate this possibility by examining the morphology of gastric mucosa before and after diversion of bile in a series of patients who had undergone gastric operations.

\section{Patients and methods}

Patients included were those in whom bile was diverted either by the formation of a Roux loop or by closure of a gastrojejunostomy. All patients had symptoms attributed to enterogastric reflux of bile, the dumping syndrome, or postvagotomy diarrhoea. In no patient was the operation undertaken for recurrent ulceration. In all cases gastric mucosal biopsy specimens were taken before and after the operation to divert bile. Random preoperative biopsy specimens were taken at endoscopy, before the operation, or at the time of the operation. Random postoperative biopsy specimens were taken at endoscopy a minimum of 10 months after operation. Ethical committee approval was obtained for the study.

All biopsy specimens were collected in formalin, fixed in mercuric formol embedded in wax, and stained with haematoxylin and eosin. All identification marks on the microscopic slides were obscured and replaced by numbers so that the observers had no knowledge of which patient the specimens were from or whether they had been obtained preoperatively or postoperatively. All were assessed by two observers (JMS, PCHW) simultaneously using a double headed microscopy, and each specimen was assessed for gastritis, atrophy, intestinal metaplasia, and dysplasia. Each of these variables was given a score from 0 to 6 .

To aid reproducibility photographs were taken of specimens that were scored 1,3 , and 5 . These were used as standards with which to compare all other specimens.

Dysplasia-Scoring for dysplasia was based on the criteria of Morson et $a l^{1}$ as follows: $0=$ no dysplasia, $1=$ focal mild, $2=$ widespread mild, $3=$ focal moderate, $4=$ widespread moderate, $5=$ focal severe, $6=$ widespread severe.

Intestinal metaplasia-A score of 1 meant that one or two gastric pits of the specimen were affected; 3 that roughly half the pits were affected; and 5 that virtually all the pits were affected.

Atrophy-A score of 1 indicated minimal loss of specialised cells; of 3 that about half the specialised cells were missing; and of 5 that virtually all specialised cells were missing. Different standard photographs were used for body and antral mucosa.

TABLE I-Dysplasia in individual biopsy specimens before and after operation to divert bile $(n=33)$ (figures are numbers $(\%)$ of specimens)

\begin{tabular}{lcc}
\hline Dysplasia score & Before & After \\
\hline 0 : No dysplasia & $79(64 \cdot 7)$ & $148(91 \cdot 9)$ \\
1: Focal mild & $18(14 \cdot 8)$ & $8(4 \cdot 9)$ \\
2: Widespread mild & $13(10 \cdot 7)$ & $3(1 \cdot 9)$ \\
3: Focal moderate & $9(7 \cdot 4)$ & $2(1 \cdot 3)$ \\
4: Widespread moderate & $3(2 \cdot 4)$ & \\
5: Focal severe & & \\
6: Widespread severe & & \\
\hline \multicolumn{1}{c}{ Total } & 122 & 161 \\
\hline
\end{tabular}

Gastritis-The score for gastritis was based on the number and type of inflammatory cells in the lamina propria. A score of 1 indicated a mild infiltrate of chronic inflammatory cells, confined to the superficial lamina propria and equivalent to "mild chronic superficial gastritis." A score of 3 indicated that there was a heavy infiltrate of chronic inflammatory cells throughout the lamina propria. Most of these had some associated atrophy equivalent to "chronic atrophic gastritis." A score of 5 indicated that there was a heavy infiltrate of acute as well as chronic inflammatory cells and often large numbers of intraepithelial neutrophils.

Preoperative and postoperative scores were calculated for each of these four variables for each patient by taking the average score of all the preoperative and postoperative specimens obtained from that patient. For the purposes of this report the terms preoperative and postoperative refer to before or after the procedure to divert the bile. Preoperative and postoperative scores for each variable were compared statistically using the Wilcoxon test. In the case of dysplasia the findings in each individual specimen are also given, but no statistical analysis was carried out on these data as the specimens did not represent independent variables. The worst dysplasia found in each patient is also given, but again this was not analysed statistically since more specimens were taken postoperatively than preoperatively. As a measure of reproducibility a proportion of the specimens was assessed a second time unknown to the observers. The first and second assessments were compared for reproducibility of scoring with Kendall's correlation coefficient.

\section{Results}

Thirty three patients entered the study group. In 14 patients a gastrojejunostomy was closed. In 19 patients a Roux loop was fashioned, after previous gastrectomy in 14 patients, vagotomy and pyloroplasty in three, and vagotomy and gastrojejunostomy in two. The average age of the patients at the time of their first operation was 38.3 years and at the time of the operation to divert bile 51 years. Before the operation to divert bile 24 patients had complained of vomiting bile, two of burning epigastric pain, 10 of dumping symptoms, and seven of diarrhoea.

All patients in our practice who require further gastric surgery are categorised as Visick grade 4 . Visick grades postoperatively were: grade 1,18 patients; grade 2,11 patients; and grade 3 , four patients.

The mean time between preoperative biopsy and the operation to divert bile was 8.4 (SD $9 \cdot 6$ ) weeks. In seven patients biopsy specimens were taken at the time of surgery, and the maximum time between preoperative biopsy and surgery was 38 weeks. Postoperative biopsy specimens were taken a minimum of 10 months after the operation. The mean time between the operation and postoperative biopsy was 36 months (maximum 95 months (21)).

A total of 283 biopsy specimens were assessed. Of these, 122 (mean 3.7 per patient) were taken preoperatively and 161 (mean 4.8 per patient) postoperatively.

Dysplasia-Table I shows the degree of dysplasia in each biopsy specimen. Preoperatively 15 patients showed no dysplasia and the worst dysplastic finding was mild in 11 patients and moderate in seven. The equivalent figures for the same patients postoperatively were no dysplasia in 24 , mild in seven, and moderate in two. Preoperative and postoperative dysplasia scores in each patient were then compared. In 13 patients the dysplasia score was zero both before and after bile diversion. In 17 patients the dysplasia score improved, and in three patients the score was worse. Table II shows the mean dysplasia scores preoperatively and postoperatively for all patients and according to the operation performed. When the preoperative and postoperative scores were compared for all patients there was a significant improvement after bile diversion $(p=0.002)$. The same was true when only patients in whom a Roux loop was fashioned were compared ( $p=$ 0.006 ). When only patients who underwent closure of gastrojejuno-

\begin{tabular}{|c|c|c|c|c|c|c|c|c|c|}
\hline & \multicolumn{3}{|c|}{ All patients } & \multicolumn{3}{|c|}{ Roux loop } & \multicolumn{3}{|c|}{ Closure of gastrojejunostomy } \\
\hline & Before & After & Significance & Before & After & Significance & Before & After & Significance \\
\hline $\begin{array}{l}\text { Gastritis } \\
\text { Atrophy } \\
\text { Intestinal metaplasia } \\
\text { Dysplasia }\end{array}$ & $\begin{array}{l}1.75(0.7) \\
2.05(0.9) \\
0.2(0 \cdot 4) \\
0.7(0.8)\end{array}$ & $\begin{array}{l}1.82(0.8) \\
1.95(1.2) \\
0.3(0.5) \\
0.2(0.3)\end{array}$ & $\begin{array}{l}\text { NS } \\
\text { NS } \\
\text { NS } \\
\mathrm{p}=0.002\end{array}$ & $\begin{array}{l}1.7(0.7) \\
1.9(0.8) \\
0.3(0.6) \\
0.85(0.96)\end{array}$ & $\begin{array}{l}1 \cdot 8(0 \cdot 8) \\
1.9(1 \cdot 2) \\
0 \cdot 3(0 \cdot 7) \\
0 \cdot 13(0 \cdot 3)\end{array}$ & $\begin{array}{l}\text { NS } \\
\text { NS } \\
\mathrm{N}=0.006\end{array}$ & $\begin{array}{l}1 \cdot 8(0 \cdot 7) \\
2 \cdot 2(1 \cdot 0) \\
0 \cdot 18(0 \cdot 4) \\
0 \cdot 5(0 \cdot 7)\end{array}$ & $\begin{array}{l}1 \cdot 8(0 \cdot 7) \\
2 \cdot 0(1 \cdot 3) \\
0 \cdot 19(0 \cdot 25) \\
0 \cdot 2(0 \cdot 4)\end{array}$ & $\begin{array}{l}\text { NS } \\
\text { NS } \\
\text { NS }\end{array}$ \\
\hline
\end{tabular}


stomy were compared the average dysplasia scores fell postoperatively, but this did not reach significance.

Intestinal metaplasia-The average score tended to be higher in the postoperative biopsy specimens for both of the operations performed, but the difference was small and did not reach significance (table II).

Atrophy-The mean score did not differ significantly between the preoperative and postoperative specimens (table II).

Gastritis-There was an overall slight increase in the average score for gastritis in the postoperative biopsy specimens, but the difference was not significant (table II).

Forty specimens were assessed a second time by the same observers. There was a highly significant correlation $(p<0.0001)$ between the first and second assessments for each of the four variables.

\section{Discussion}

Symptomatic improvement after procedures to divert bile is good. We have previously reported good clinical results after both formation of a Roux loop ${ }^{10}$ and closure of gastrojejunostomy. ${ }^{11}$ In our patients the improvement in symptoms was not paralleled by improvement in gastritis. An experimental study showed that gastritis was induced in five out of 12 dogs by partial gastrectomy and that subsequent transposition of a jejunal segment with an intussusception valve resulted in return of the gastric mucosa to normal. ${ }^{12}$ Mosimann et al, however, found that, although they could induce gastritis in dogs by diverting bile and pancreatic fluid into the stomach, they could not show any improvement in chronic inflammation in eight people who had undergone Roux en $\mathrm{Y}$ gastrojejunostomy for reflux gastritis. ${ }^{13}$ School $e t$ al also found no improvement three months after Roux en $\mathrm{Y}$ diversion in six patients, ${ }^{14}$ and Hoare et al found no improvement in 16 patients. ${ }^{15}$ The evidence suggests that changes in gastritis occurring in experimental animals cannot be extrapolated to man. This is not surprising as the animals' stomachs are presumably normal whereas the human stomach has been operated on for previous gastric or duodenal ulcer, both of which are associated with gastritis per se. ${ }^{16}$

The disparity between histological gastritis and symptoms found in our 33 patients has been noted by others in both stomachs that have not $^{17}$ and stomachs that have ${ }^{18}$ been operated on.

The long term natural history of dysplasia remains unknown. Stokkeland et al found no progression of dysplasia in patients who underwent two endoscopies three years apart. ${ }^{19}$ Farini et al followed up 18 patients with moderate and severe dysplasia by endoscopy for six or 12 months and found that, whereas two cases progressed to carcinoma, regression also commonly occurred. ${ }^{20}$ It is difficult to be sure, however, whether true progression and regression took place as opposed to purely sampling differences between the endoscopic examinations. Similarly in our own study we cannot be sure that the dysplasia in one gastric gland or cell regressed. To have taken biopsy specimens from fixed areas before and after operation might have been misleading as accurate mapping would be extremely difficult in view of the anatomical change and distortion effected by the operation. Additionally, the areas affected by dysplasia tended to be patchy, even within one biopsy specimen, and accurate mapping on this scale is clearly impossible. The fact that statistically less dysplasia was found in random biopsy samples after diversion of bile does at least suggest the possibility that the dysplasia did regress. The fact that no case of severe dysplasia was seen either preoperatively or postoperatively, however, means that our findings are confined to moderate and mild dysplasia.

Our findings suggest that reflux of the small-bowel contents into the stomach is important in the pathogenesis of gastric dysplasia in these patients. This agrees with the opinion of Domellof $e t a l^{4}$ and the finding of Thomas et $a l^{21}$ of a positive correlation between bile reflux and gastric mucosal dysplasia. As the natural history of gastric dysplasia is uncertain we cannot advocate diversion of bile as a treatment for patients in whom dysplasia is found. If in the future dysplasia is found to have considerable premalignant potential, however, then diversion of bile may be considered at least in those patients in whom pro- $Q$ gressive abnormalities are found in sequential endoscopies.

No difference in the incidence of intestinal metaplasia was $\curvearrowright$ found. This is not surprising as it is uncertain whether gastric mucosa that has undergone metaplasia can revert to normal. The fact that no increase in intestinal metaplasia occurred raises the क possibility that the diversion of bile halted its progression. This point also applies to mucosal atrophy, which also did not progress.

Our conclusions are that diversion of bile away from the $\overrightarrow{0}$ stomach postoperatively leads to an improvement in gastric $\underline{\underline{O}}$ mucosal dysplasia. The importance of this finding can be assessed in detail only when the natural history of dysplasia is $\stackrel{\mathbb{Q}}{\circ}$ fully elucidated.

PCHW was in receipt of a Royal Victoria Hospital fellowship $\vec{\circ}$ throughout the study. Mr C C Patterson, department of medical $\overrightarrow{\vec{H}}$ statistics, Queen's University, Belfast, advised on statistical analysis. $\vec{\omega}$ $\mathrm{Mr} \mathrm{J}$ Reid and staff of the histopathology laboratory, department of $\frac{\rho}{\partial}$ pathology, Royal Victoria Hospital, made all the microscopic slides. 3 We thank Smith, Kline and French Research Ltd and the Mater iv Infirmorum Hospital gifts and endowments fund for financial support.

\section{References}

${ }^{1}$ Morson BS, Sobin CH, Grundmann E, Johansen A, Nagayo T, Serck- 윽 Hanssen A. Precancerous conditions and epithelial dysplasia in the $\vec{N}$ stomach. f Clin Pathol 1980;33:711-21.

${ }^{2}$ Serck-Hanssen A. Precancerous lesions of the stomach. Scand $\mathcal{f}$ Gastro- Z enterol [Suppl] 1979;14:104-5.

3 Schrumpf E, Serck-Hanssen A, Stadaaj J, Aune S, Myren O, Osnes M. Changes in the gastric stump 20-25 years after partial gastrectomy. Lancet 1977 ; ii :467-9.

4 Domellof L. Gastric carcinoma promoted by alkaline reflux gastritiswith special reference to bile and other surfactants as promoters of post-operative gastric cancer. Medical Hypotheses 1979;5:463-76.

5 Domellof L, Reddy BS, Weisburger JH. Microflora and deconjugation of bile acids in alkaline reflux after partial gastrectomy. Am f Surg 1980; 140:291-5.

${ }^{6}$ Reddy BS, Narasawa J, Weisburger JH. Promoting effect of sodium deoxycholate in colon adenocarcinoma in germ free rats. $\mathcal{F} N C I 1976 ; \mathbf{5 6}$ : 441-2.

7 Du Plessis DJ. Gastric mucosal changes after operations on the stomach. $S$ A Med f 1962;36:471-8.

${ }^{3}$ Ritchie WP. Alkaline reflux gastritis. An objective assessment of its diagnosis and treatment. Ann Surg 1980;192:288-98.

${ }^{9}$ Silen W. Malevolent gall. Surgery 1972;71:311-2.

10 Kennedy T, Green R. Roux diversion for bile reflux following gastric surgery. Br F Surg 1978;65:323-5

11 Green R, Spencer A, Kennedy T. Closure of gastrojejunostomy for the relief of post-vagotomy symptoms. Br $\mathcal{F}$ Surg 1978;65:161-3.

12 Svensson JO, Hansson G. Gastric and intestinal mucosal morphology before and after interposition of a reflux presenting valve between the gastric remnant and the duodenum. Acta Chir Scand 1980;146:597-603.

${ }^{13}$ Mosimann F, Burri B, Diserens H, Fontolliet C, Loup P, Mosimann R. ठ Enterogastric reflux: experimental and clinical study. Scand $\mathcal{f}$ Gastroenterol [Suppl] $1981 ; 67: 149-52$.

14 Schoon IMM, Andersson H, Faxen A, Olbe L. Gastric bile acids before 윽 and after Roux en $\mathrm{Y}$ transposition for bile reflux gastritis and in $N$ asymptomatic controls. Scand f Gastroenterol 1979;14:969-76.

15 Hoare AM, McLeish A, Thompson H, Alexander-Williams J. Selection of patients for bile diversion surgery: use of bile acid measurements in fasting gastric aspirates. Gut 1978;19:163-5.

16 Lambert R. Chronic gastritis. Digestion 1972; $7: 83-126$

17 Siurala M, Isokoski M, Varis K, Kekkl M. Prevalence of gastritis in a

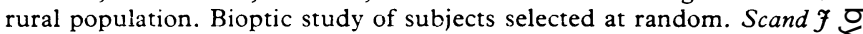
Gastroenterol 1968:3:211-23.

${ }^{18}$ Keighley MRB, Asquith P, Alexander-Williams J. Duodenogastric reflux: a cause of gastric mucosal hyperaemia and symptoms after operations for peptic ulceration. Gut $1975 ; \mathbf{1 6}: 28-32$.

19 Stokkeland M, Schrumpf E, Serck-Hanssen A, Myren J, Osnes M, Stadaas J. Incidence of malignancies of the Billroth II operated stomach. $\mathrm{O}$ Scand 7 Gastroenterol [Suppl] $1981 ; 67: 169-71$.

${ }^{20}$ Farini R, Cardin F, Arslan-Pagnini C, et al. Gastric carcinoma during $\frac{\bigcirc}{\Phi}$ follow-up of moderate or severe gastric epithelial dysplasia [Abstract]. Gut 1983;24:A493.

21 Thomas WEG, Cooper MJ, Mortensen NJ, Burton P, Davies ER. Positive correlation between duodenogastric reflux and gastric dysplasia [Abstract]. Gut 1983;24:A476.

(Accepted 2 August 1983) 